\title{
Atitudes dos jovens portugueses face à publicidade contemporânea: uma análise das caraterísticas e dos efeitos do fenómeno publicitário
}

\author{
Paulo Ribeiro Cardoso ${ }^{1}$ \\ Elsa Simões Lucas Freitas ${ }^{2}$ \\ Clara Pereira Lopes ${ }^{3}$
}

Recibido: 2016-01-25

Enviado a pares: 2016-02-09
Aprobado por pares: 2016-03-16

Aceptado: 2016-04-07

DOI: 10.5294/pacla.2017.20.2.7

Para citar este artículo / to reference this article / para citar este artigo Ribeiro Cardoso, P., Lucas Freitas, E.S. y Pereira Lopes, C. (2017). Atitudes dos jovens portugueses face à publicidade contemporânea: uma análise das caraterísticas e dos efeitos do fenómeno publicitário. Palabra Clave, 20(2), 444-472. DOI: 10.5294/pacla.2017.20.2.7

\section{Resumo}

Frequentemente, as pessoas manifestam sentimentos ambivalentes relativamente à influência e ao impacto que a publicidade detém na nossa sociedade contemporânea. Neste estudo, de carácter quantitativo, pretende-se analisar a atitude dos públicos face à publicidade, partindo do modelo proposto por Pollay e Mittal (1993), utilizando uma amostra de 210 jovens portugueses. Verificamos que, em geral, os participantes têm uma atitude positiva quanto à publicidade. Os resultados mostram que, em geral, eles consideram que a publicidade transmite informação sobre os produtos e que, simultaneamente, é uma fonte de entretenimento para os consumidores. Em termos socioeconómicos, salientam-se as convicções de que a publici-

1 orcid.org/0000-0002-4643-8716. Universidade Fernando Pessoa. Portugal. pjrcardoso@gmail.com

2 Universidade Lusíada do Porto; Universidade Fernando Pessoa. Portugal. esimoes@ufp.edu.pt

3 Universidade Fernando Pessoa. Portugal. claralope@gmail.com 
dade é positiva para o desenvolvimento da economia, mas que, por outro lado, pode ser prejudicial para a sociedade, nomeadamente na corrupção de valores, no estímulo ao materialismo e na transmissão de mensagens enganosas. A partir de uma regressão linear, verifica-se que é possível predizer a atitude perante a publicidade por meio de quatro fatores: o papel informativo da publicidade, o seu papel hedónico, os benefícios da publicidade para a economia e a corrupção de valores por parte da publicidade. Constata-se também que a atitude face à publicidade tem impacto na decisão de compra.

\section{Palavras-chave}

Atitude face à publicidade; consumidores; fatores socioeconómicos da publicidade; mensagem publicitária (Fonte: Tesauro da Unesco). 


\section{Actitudes de los jóvenes portugueses frente a la publicidad contemporánea: un análisis de las características y los efectos del fenómeno publicitario}

\section{Resumen}

Frecuentemente, las personas manifiestan sentimientos ambivalentes en relación con la influencia y el impacto que la publicidad tiene en nuestra sociedad contemporánea. En este estudio, de carácter cuantitativo, se pretende analizar la actitud de los públicos frente a la publicidad, partiendo del modelo propuesto por Pollay y Mittal (1993), utilizando una muestra de 210 jóvenes portugueses. Verificamos que, por lo general, los participantes tienen una actitud positiva hacia la publicidad. Los resultados muestran que, en general, ellos consideran que la publicidad transmite información sobre los productos y que, a la vez, es una fuente de entretenimiento para los consumidores. En términos socioeconómicos, se destacan las convicciones de que la publicidad es positiva para el desarrollo de la economía, pero que, por otro lado, puede ser perjudicial para la sociedad, nombrada en la corrupción de valores, en el estímulo al materialismo y en la transmisión de mensajes engañosos. A partir de una regresión linear, se puede verificar que es posible predecir la actitud ante la publicidad por medio de cuatro factores: el papel informativo de la publicidad, o su papel hedónico, los beneficios de la publicidad para la economía y la corrupción de valores por parte de la publicidad. También se constata que la actitud frente a la publicidad tiene impacto en la decisión de compra.

\section{Palabras clave}

Actitud frente a la publicidad; consumidores; factores socioeconómicos de la publicidad; mensaje publicitario (Fuente: Tesauro de la Unesco). 


\section{Attitude of Portuguese Youth towards Contemporary Advertising: An Analysis of the Characteristics and Effects of the Advertising Phenomenon}

\section{Abstract}

People often express ambivalent feelings about the influence and impact of advertising on our contemporary society. In this quantitative study, we aim to analyze the audience's attitude towards advertising, based on the model proposed by Pollay e Mittal (1993), using a sample of 210 Portuguese young men and women. We verified that, in general terms, participants have a positive attitude regarding publicity. Results show that they generally believe that advertising conveys information about products and that at the same time it is a source of entertainment for consumers. In socio-economic terms, there is a strong belief that advertising is positive for the development of the economy but that, on the other hand, it can be detrimental to society, particularly in the corruption of values, the encouragement of materialism and the transmission of misleading messages. Based on a linear regression, we find that it is possible to predict the attitude towards advertising through four factors: the informative role of advertising, its hedonic role, the benefits of advertising for the economy and the corruption of values by advertising. We also find that the attitude towards advertising has an impact on the purchase decision.

\section{Keywords}

Attitude towards advertising; consumers; socio-economic factors of advertising; advertising message (Source: Unesco Thesaurus). 


\section{Introdução}

A publicidade suscita reações diversas nos diferentes consumidores eleituras ambivalentes no que diz respeito ao modo como o indivíduo encara a omnipresença da comunicação publicitária. A publicidade é um fator modelador e condicionador de comportamentos sociais (ver, entre outros, Freitas, 2008 e 2014; Marin, Pizzinato e Giuliani, 2014). Assim, é muito importante procurar compreender os modos como essas diferentes perceções se conjugam na mente dos consumidores. O resultado poderá ser uma leitura fragmentada e contraditória perante um fenómeno polémico. É possível nele reconhecer qualidades positivas e propiciadoras de uma vida hedónica em sociedade (entretenimento e progresso económico). Por outro lado, a publicidade pode apresentar-se como corruptora dos valores básicos, já que incita ao consumo e apela a uma certa superficialidade das vivências sociais.

Quando nos questionamos sobre as marcas e a forma como elas são divulgadas no seu entorno social, a comunicação publicitária continua a representar a "voz" promocional por excelência, estando presente na nossa realidade quotidiana a vários níveis. Hoje em dia, frequentemente assistimos nas redes sociais à proliferação dos canais on-line e à divulgação de marcas e produtos (Cunha e Freitas, 2010). No entanto, a nossa consciência do fenómeno publicitário, na sua globalidade, ainda se centra principalmente nas formas mais convencionais de publicidade, veiculadas pelos meios tradicionais. $\mathrm{O}$ nosso entendimento do fenómeno está ainda fortemente associado a manifestações com contornos definidos, tais como anúncios de televisão ou de imprensa. Esse facto legitima a pergunta que norteia o nosso estudo: como percecionamos a publicidade contemporânea?

Este estudo aborda a problemática do consumidor face à publicidade fazendo, mais concretamente, uma análise das caraterísticas e dos efeitos do fenómeno publicitário, e partindo do modelo proposto por Pollay e Mittal (1993). O cenário escolhido para esta investigação foi o contexto publicitário português.

Tendo ganhado particular impulso na década de 1960, foi porém nos anos 1980 que a publicidade em Portugal ganhou consistência, quer en- 
quanto atividade empresarial, quer enquanto presença nos media (Cardal e Almeida, 1994). Para esse avanço, muito contribuiu a adesão de Portugal à Comunidade Europeia, o que desencadeou a entrada de um grande número de marcas internacionais em território nacional e, consequentemente, novos desafios para as marcas e as agências de publicidade portuguesas (Lindon, Lendrevie, Lévy, Dionísio e Rodrigues, 2008).

Atualmente, e apesar de um contexto económico difícil, o mercado publicitário vive uma fase de maturidade, com um tecido empresarial desse sector francamente desenvolvido. Paralelamente, verifica-se uma maior consistência por parte das marcas portuguesas relativamente ao seu know-how em marketing e publicidade. Em 2015, e segundo dados da Magna Global (unidade de estratégia global do grupo IPG Mediabrands), o investimento publicitário em Portugal estava em crescimento, alinhado pela evolução global. No âmbito nacional, o crescimento do mercado foi cerca de $4 \%$ em comparação com o ano anterior (Ribeiro, 2015). No que diz respeito aos diferentes meios publicitários, de acordo com os dados da MediaMonitor, a televisão liderou nesse ano com $75,5 \%$ dos montantes; a imprensa captou $8,7 \%$; a internet, $7,1 \%$; o outdoor, $4,7 \%$; a rádio, $3,5 \%$, e o cinema, 0,4\% (Marktest, 2015).

No que respeita ao consumo de media, e segundo dados da Entidade Reguladora para a Comunicação Social (ERC), a televisão foi, em 2015, o meio escolhido para aceder a notícias (Gazeta do Rossio, 2015). De sublinhar também que $60 \%$ da população acedeu à internet pelo menos uma vez por semana, fosse para ler notícias ou para consultar as redes sociais. Esse consumo está, de algum modo, relacionado com a exposição à publicidade pois os anunciantes escolhem os meios mais acedidos pelos consumidores para neles inserirem as suas mensagens comerciais (Gazeta do Rossio, 2015).

De facto, quando falamos da receção da publicidade e da opinião que os consumidores formam acerca desta, estamos a referir-nos aos anúncios que são veiculados nos meios de comunicação de massa, lado a lado com outros conteúdos, tais como a informação e o entretenimento. 
O modelo de Pollay e Mittal, enquanto ferramenta de análise sobre a perspetiva dos consumidores com relação à comunicação publicitária, foi já utilizado em investigações anteriores, em outros contextos geográficos (Yang, 2000; Petrovici e Paliwoda, 2007; Marinov, Petrovici e Marinova, 2008). Contudo, não foram identificados estudos que tivessem aplicado esse modelo no território português. Nesse âmbito, a presente análise tem um duplo objetivo de carácter geral. Por um lado, e numa perspetiva essencialmente exploratória, pretende-se analisar a aplicabilidade do instrumento criado pelos autores à população portuguesa, mais concretamente aos consumidores jovens adultos. Por outro lado, procura-se analisar a atitude desse segmento face à publicidade e a sua influência no processo de decisão de compra.

O nosso estudo seguiu uma abordagem quantitativa, tendo-se utilizado uma amostra não probabilística de conveniência, composta por 210 indivíduos de ambos os sexos e com idades compreendidas entre os $18 \mathrm{e}$ os 35 anos. O questionário baseou-se fundamentalmente no modelo, e respetivo instrumento, criado por Pollay e Mittal (1993).

Após a análise dos dados recolhidos por meio do questionário, são apresentadas, no final deste artigo, a discussão dos resultados e as principais conclusões.

\section{Revisão de literatura}

\section{A publicidade contemporânea e o seu impacto no consumidor} Hoje em dia, é inegável a presença da publicidade em praticamente todas as nossas atividades quotidianas. Esse caráter intrusivo dos anúncios é um dos motivos pelos quais eles são constantemente remetidos para um segundo plano na nossa atenção: não é nunca a publicidade que nós queremos realmente ver ou ouvir. Simplesmente, os anúncios posicionam-se à margem do que realmente nos interessa, utilizando para seu proveito os interstícios deixados vagos pelos outros discursos, aproveitando, desse modo, os resquícios da nossa atenção, operando de modo fragmentário e transmitindo a sua mensagem de forma parcelar (Freitas, 2008). Como quase 
nunca pode dispor da atenção total de quem a vê ou ouve (Cornelis, Adams e Cauberghe, 2012), a publicidade tem de recorrer a mensagens que sejam simples, fáceis de apreender e que apostem numa complexa rede de repetições a nível interno. Nessas mensagens, todos os canais veiculam os mesmos significados por meio de diferentes sistemas de signos dentro de um único anúncio. A nível externo, também há efeito de repetição, com os vários meios a veicular a mesma mensagem global, de modo a aumentar as possibilidades de atingir o máximo de consumidores.

Talvez, devido à sua grande familiaridade com o discurso publicitário, os consumidores tenham relutância em atribuir-lhe credibilidade. $\mathrm{O}$ caráter repetitivo dos anúncios e a facilidade com que todas as mensagens são compreendidas fazem com que a publicidade se torne alvo de críticas. Esse facto pode minimizar as suas potenciais qualidades enquanto discurso e responsabilizá-lo por comportamentos consumistas irresponsáveis (Freitas e Tuna, 2015).

\section{Crenças e atitude face à publicidade}

Os consumidores exibem um conjunto de crenças profundamente enraizadas com relação à publicidade, quer ao nível da mensagem publicitária propriamente dita, quer ao nível da publicidade como entidade presente na nossa sociedade. Em função dessas crenças, os indivíduos constroem uma atitude face à publicidade em geral que pode, direta ou indiretamente, ter impacto no processo de decisão de compra. Pollay e Mittal (1993) procuraram analisar esse fenómeno mediante um modelo que permite explicar a atitude dos consumidores no que se refere à publicidade. Para esse efeito, dividiram-no em três componentes.

Relativamente à primeira componente, os autores consideraram os fatores que explicam a utilidade da publicidade ao nível pessoal, os quais têm um caráter mais pessoal e mais específico. Nesse grupo de fatores, incluem-se a função da publicidade na transmissão de informação sobre o produto e a sua capacidade de transmitir novidades sobre o mercado. Inclui-se também nesse mesmo grupo a função social da publicidade, ou seja, a transmissão de estilos de vida e de referências sociais que permitem ao consumidor situar-se 
nas suas escolhas e projetar-se nesses mesmos valores. Finalmente, a nível pessoal, o visionamento de anúncios publicitários pode ser uma experiência hedónica, compensadora ao nível do entretenimento (tal como apontam, entre outros, Williams e Drolet, 2005; Silva, Torres e Freitas, 2014).

Na segunda componente, os autores consideraram a perspetiva dos consumidores perante os efeitos sociais e culturais da publicidade. Esses fatores têm um caráter mais generalizado e mais abstrato. Nesse contexto, a publicidade pode ser considerada positiva para a economia, permitindo às empresas reduzirem o custo dos produtos e promoverem a concorrência saudável entre as marcas. Por outro lado, a publicidade pode ter consequências negativas para a sociedade, sendo, por exemplo, incitadora do materialismo (Freitas e Tuna, 2010). Ela pode também ser deturpadora dos valores, reforçando os sete pecados (gula, avareza, luxúria, ira, inveja, preguiça e vaidade) em vez das sete virtudes (temperança, generosidade, castidade, paciência, caridade, diligência, humildade). Finalmente, ela pode ser considerada enganosa ou, pelo menos, superficial, confusa ou sem sentido.

A terceira componente do modelo contempla a atitude geral face à publicidade. Essa atitude resulta diretamente dos fatores anteriormente mencionados. Ou seja, partindo do modelo em questão, essa atitude resulta, de alguma forma, da utilidade da publicidade ao nível pessoal e dos efeitos sociais e culturais da publicidade.

\section{Abordagens ao modelo de Pollay e Mittal}

A atitude dos consumidores diante da publicidade tem sido objeto de estudos académicos nos últimos cinquenta anos (Greyser e Bauer, 1966; Larkin, 1977; Muehling, 1987; Shavitt, Lowrey e Haefner, 1998; Dutta-Bergman, 2006). As perspetivas de abordagem do tema têm sido diversas, contemplando variáveis como a "utilidade social dos anúncios publicitários", o "consumo de televisão" e a "comunicação entre pares" (Bush, Smith e Martin, 1999), a "opinião sobre as marcas" e o "grau de conhecimento sobre o mercado" (Hilliard, Matulich, Haytko e Rustogi, 2012), o "materialismo e vaidade" (Mady, Cherrier, Lee e Rahman, 2011) e a "evitação da publicidade" (Prendergast, Wah-leung e West, 2010). 
A abordagem de Pollay e Mittal (1993) é, possivelmente, a mais recorrente na literatura do marketing e da publicidade. Desde a sua publicação até à atualidade, o modelo foi aplicado em diversos contextos geográficos, procurando aferir quais as atitudes dos consumidores perante a comunicação publicitária.

Em alguns estudos levados a cabo no início deste século, podemos constatar que as investigações se desenvolvem a nível global, incidindo sobre a Europa (Martin-Santana e Beerli-Palacio, 2008, por exemplo), Ásia (Ramaprasad, 2001), Estados Unidos (Nan, 2006) e América do Sul (Dávila e Rojas-Méndez, 2001). Essa extensão geográfica demonstra bem a universalidade desse tema e o interesse que representa no contexto académico e empresarial. A população-alvo desses estudos tem sido também diversa, contemplando consumidores no âmbito das suas compras (Nan, 2006), assim como estudantes contextualizados em amostras de conveniência (Dávila e Rojas-Méndez, 2001).

Ao nível dos fatores analisados, os estudos identificam, geralmente, as dimensões propostas por Pollay e Mittal (1993). Porém, em alguns casos, essas dimensões surgem fundidas num só fator, como por exemplo, "materialismo/corrupção de valores” (Martin-Santana e Beerli-Palacio, 2008) ou identificadas com designações diferentes das originais, tais como "intrusão" (Nan, 2006) ou "alienação" (Marinov et al., 2008). Finalmente, alguns autores optaram por utilizar apenas uma parte do modelo, circunscrevendo, por exemplo, o estudo às dimensões individuais (Petrovici e Paliwoda, 2007).

Em suma, esse pequeno conjunto de estudos demonstra a importância e a transversalidade do modelo ao nível geográfico e a pertinência dessa temática nos tempos atuais.

\section{Objetivos de investigação}

Na sequência da observação do fenómeno publicitário contemporâneo e da análise da literatura existente sobre as posturas face à publicidade, este estudo pretende, então, investigar as atitudes dos jovens portugueses quanto à publicidade contemporânea utilizando, para isso, uma adaptação do instrumento criado por Pollay e Mittal (1993). 
Especificamente, propomos os objetivos de investigação descritos a seguir.

1. Confirmar a consistência das dimensões propostas no modelo de Pollay e Mittal no contexto de uma amostra de jovens consumidores portugueses.

2. Avaliar até que ponto os jovens consumidores têm presente a utilidade da publicidade ao nível pessoal e estão conscientes dos efeitos sociais e culturais da publicidade, tal como foram colocados por Pollay e Mittal.

3. Avaliar a atitude geral face à publicidade.

4. Avaliar até que ponto a publicidade tem influência na decisão de compra.

5. Verificar a relação entre as crenças relativas à publicidade, a atitude relativamente à publicidade e a influência desta na decisão de compra.

6. Aferir quais as dimensões que permitem predizer a atitude perante a publicidade e qual o impacto desta no processo de decisão de compra.

\section{Método}

O presente estudo, de caráter quantitativo, utilizou uma amostra de conveniência, constituída por 210 sujeitos, com idades compreendidas entre os 18 e os 35 anos. Como instrumento de recolha de dados, foi administrado um questionário entre maio e julho de 2010, numa Universidade da cidade do Porto, a segunda maior cidade de Portugal. De modo a poder aceder a um conjunto de indivíduos com alguma diversidade ao nível do seu perfil demográfico, foram contemplados, nesta amostra, alunos e colaboradores da referida universidade. $\mathrm{O}$ questionário foi apresentado em formato impresso, com as informações e as instruções necessárias para ser preenchido pelos próprios inquiridos, sem a intervenção de um entrevistador. Os exemplares do questionário foram distribuídos aos inquiridos pelos investigadores, tendo sido dada a indicação de um cacifo para respetiva devolução, preservando assim a confidencialidade da identidade dos sujeitos. A taxa de resposta obtida foi de $95 \%$.

O questionário baseou-se fundamentalmente no modelo, e respetivo instrumento, criado por Pollay e Mittal (1993). Tal como anteriormente 
descrito na revisão de literatura deste artigo, o modelo é composto por três componentes. A primeira, relativa à utilidade da publicidade ao nível pessoal, é composta por três dimensões, cada uma delas medida por três itens. A segunda componente, relativa aos efeitos sociais e culturais da publicidade, é composta por quatro dimensões, igualmente avaliadas por meio de três itens (à exceção da dimensão "corrupção de valores”, composta por quatro itens). Finalmente, a terceira componente, relativa à atitude geral sobre a publicidade, é também medida por meio de três itens. Em todos os itens, foi usada uma escala de Likert de cinco pontos: 1 = discordo totalmente; 2 $=$ discordo; 3 = indiferente $4=$ concordo $; 5=$ concordo totalmente.

Às questões relativas a esse modelo foi acrescentada uma dimensão de caráter predominantemente comportamental: a influência que a publicidade pode ter na decisão de compra do consumidor. Essa dimensão avalia até que ponto os anúncios publicitários ajudam os consumidores a recordarem os produtos e as marcas, a gerarem opiniões e sentimentos acerca destes e a tomarem decisões de compra. Essa dimensão é composta por quatro itens, também avaliados por uma escala de Likert de cinco pontos: $1=$ discordo totalmente; 2 = discordo; 3 = indiferente; $4=$ concordo; $5=$ concordo totalmente.

Incluiu-se também no instrumento um conjunto de questões demográficas, constituído por idade, sexo, habilitações académicas e município de residência, no sentido de traçar o perfil da amostra estudada.

\section{Análise de dados}

\section{Caraterização da amostra}

A amostra do presente estudo foi constituída por 210 indivíduos, sendo $51,4 \%$ do sexo feminino e $48,6 \%$ do sexo masculino (Tabela 1 ). Quanto à idade, 51,4\% tinham entre 18 e 25 anos, e 48,6\%, entre 26 e 35 anos. Relativamente às habilitações académicas, $60 \%$ dos participantes possuíam habilitações até ao Ensino Secundário, 34,3\% eram licenciados, 5,7\% possuíam uma pós-graduação ou o grau de Mestre. Os entrevistados eram, todos eles, residentes em zonas urbanas, maioritariamente da Área Metropolitana do 
Porto (72\%), e de outros municípios do Norte de Portugal (28\%), tais como Braga, Guimarães, Barcelos, Amarante e Vila Real.

\section{Tabela 1. Caraterização demográfica da amostra}

\begin{tabular}{|l|c|c|}
\hline \multicolumn{1}{|c|}{ Variáveis demográficas } & Frequências & Percentagens \\
\hline Género & & \\
\hline Feminino & 108 & 51,4 \\
\hline Masculino & 102 & 48,6 \\
\hline Faixas etárias & & \\
\hline 18 -25 & 108 & 51,4 \\
\hline $26-35$ & 102 & 48,6 \\
\hline Habilitações académicas & & \\
\hline Ensino Secundário & 126 & 60 \\
\hline Licenciatura & 72 & 34,3 \\
\hline Pós-graduação/Mestrado & 12 & 5,7 \\
\hline Concelho de residência & & \\
\hline Área Metropolitana do Porto (Porto, Gaia, Matosinhos, Maia e Gondomar) & 151 & 7 \\
\hline $\begin{array}{l}\text { Outras cidades do Norte de Portugal } \\
\text { (Braga, Guimarães, Barcelos, Amarante e Vila Real) }\end{array}$ & 59 & 28 \\
\hline Total & 210 & 100,0 \\
\hline
\end{tabular}

Fonte: elaboração dos autores.

\section{Consistência interna das dimensões}

Nesta investigação, os entrevistados foram confrontados com um conjunto de afirmações sobre as quais deveriam manifestar a sua concordância ou discordância. De acordo com o modelo de Pollay e Mittal (1993), essas afirmações estavam agregadas em dimensões, ou seja, a resposta a um conjunto de itens permite avaliar um determinado conceito. Dado que na revisão de literatura não foi encontrada a aplicação dessa escala em território português, este trabalho serve como um contributo exploratório sobre a sua aplicabilidade em Portugal. Nesse sentido, o primeiro objetivo deste artigo é o de confirmar a consistência das dimensões propostas no modelo de Pollay e Mittal. Sendo esse modelo composto por diversas dimensões (constituídas por sua vez por vários itens), a avaliação da fiabilidade permite ver até que ponto os itens, que constituem cada dimensão, possuem consistência entre si (Maroco e Garcia-Marques, 2006). Para verificar a 
consistência interna de cada uma das dimensões da escala, foi usado neste estudo o Alpha de Cronbach, um método que fornece estimativas do grau de consistência de uma medida e que é usado por um grande número de investigadores (Maroco e Garcia-Marques, 2006). O coeficiente de fiabilidade pode variar entre o valor de 0 e o valor de 1 (Pestana e Gageiro, 2005). Em geral, considera-se que um instrumento tem fiabilidade apropriada quando o a é, pelo menos, 0,70 (Nunnally, 1978). No caso do presente estudo, praticamente todas as dimensões apresentam valores iguais ou acima desse limite (Tabela 2). Apenas duas dimensões — "Entretenimento na publicidade" e "Benefício para a economia" - apresentam valores próximos de 0,60, o que em alguns contextos de investigação das ciências sociais é considerado aceitável (Maroco e Garcia-Marques, 2006). Como tal, optou-se por aceitar esses valores.

Para além do modelo já apresentado, procura-se neste estudo analisar uma vertente comportamental desse fenómeno. Pretende-se averiguar qual a influência da publicidade no processo de decisão de compra. Nesse sentido, foi criada uma escala unidimensional, composta por quatro itens, destinada a avaliar essa variável latente. No sentido de confirmar a usabilidade dessa escala realizou-se uma análise fatorial de componentes principais de caráter exploratório, com rotação varimax. Essa prova permite verificar até que ponto diferentes variáveis, ou itens, têm subjacente o mesmo conceito e, portanto, se agregam num mesmo fator (Pestana e Gageiro, 2005). Nesse caso, pretendia-se determinar se os quatro itens criados se agregavam num mesmo fator que media a influência da publicidade na decisão de compra.

A análise fatorial de componentes principais implica a verificação prévia de alguns indicadores. Analisando esses indicadores, constatou-se que o teste de Kaiser-Meyer-Olkin Measure $(0,743)$ e que o teste de esfericidade de Bartlett $(0,000)$ confirmaram a adequabilidade dos dados para a análise fatorial. O modelo encontrado é composto por apenas um fator e explica $59,79 \%$ da variância dos dados iniciais. A dimensão é constituída por quatro itens com valores próprios superiores a um e com cargas fatoriais entre 0,560 e 0,818 . Esse resultado permite concluir que, de facto, os quatro itens inicialmente criados têm subjacente o mesmo conceito. Seguidamente, verificou-se 
também a consistência interna dessa dimensão, tendo-se obtido um Alpha de Cronbach com o valor de $\alpha=0,754$ (Tabela 2). Tal como explicado anteriormente, esse teste faz a avaliação da fiabilidade permitindo verificar até que ponto os itens que constituem um dado fator, ou dimensão, possuem consistência entre si.

\section{Tabela 2. Consistência interna das escalas}

\begin{tabular}{|c|c|c|}
\hline Dimensões & Itens & $\begin{array}{l}\text { Alpha de } \\
\text { Cronbach }\end{array}$ \\
\hline \multicolumn{3}{|c|}{ Utilidade da publicidade ao nível pessoal } \\
\hline \multirow{3}{*}{$\begin{array}{l}\text { Papel } \\
\text { informativo }\end{array}$} & $\begin{array}{l}\text { A publicidade ajuda a manter-me atualizado(a) sobre os produtos/serviços disponíveis } \\
\text { no mercado. }\end{array}$ & \multirow{3}{*}{0,735} \\
\hline & A publicidade diz-me quais as marcas que têm as caraterísticas que eu procuro. & \\
\hline & $\begin{array}{l}\text { A publicidade é uma fonte de informação valiosa sobre os produtos que se vendem na } \\
\text { minha cidade. }\end{array}$ & \\
\hline \multirow{3}{*}{ Papel social } & $\begin{array}{l}\text { A publicidade ajuda-me a saber quais os produtos que refletem, ou não, o tipo de pessoa } \\
\text { que sou. }\end{array}$ & \multirow{3}{*}{0,759} \\
\hline & $\begin{array}{l}\text { A publicidade diz-me o que as pessoas com estilos de vida semelhantes ao meu estão a } \\
\text { comprar e a usar. }\end{array}$ & \\
\hline & Através da publicidade, vejo o que está na moda e o que comprar para impressionar os outros. & \\
\hline \multirow{3}{*}{$\begin{array}{c}\text { Papel } \\
\text { hedónico }\end{array}$} & Frequentemente, a publicidade é divertida e entretém. & \multirow{3}{*}{0,682} \\
\hline & Às vezes, gosto de pensar sobre o que vi ou ouvi ou li em anúncios publicitários. & \\
\hline & $\begin{array}{l}\text { Às vezes, os anúncios são ainda mais agradáveis do que outros conteúdos dos meios de } \\
\text { comunicação. }\end{array}$ & \\
\hline \multicolumn{3}{|c|}{ Efeitos sociais e culturais da publicidade } \\
\hline \multirow{3}{*}{ Materialismo } & $\begin{array}{l}\text { A publicidade está a tornar-nos uma sociedade materialista, demasiado interessada em } \\
\text { comprar e possuir coisas. }\end{array}$ & \multirow{3}{*}{0,778} \\
\hline & A publicidade faz com que as pessoas comprem produtos caros só para os exibir. & \\
\hline & $\begin{array}{l}\text { Por causa da publicidade, as pessoas compram muitas coisas de que realmente não } \\
\text { precisam. }\end{array}$ & \\
\hline \multirow{3}{*}{$\begin{array}{c}\text { Benefício } \\
\text { para a } \\
\text { economia }\end{array}$} & De uma forma geral, a publicidade promove a concorrência, o que beneficia o consumidor. & \multirow{3}{*}{0,606} \\
\hline & De uma forma geral, a publicidade ajuda a economia do país. & \\
\hline & Na sua maioria, a publicidade não é um desperdício de recursos económicos. & \\
\hline \multirow{3}{*}{$\begin{array}{l}\text { Falsidade e } \\
\text { contrassenso }\end{array}$} & De uma forma geral, a publicidade é enganosa. & \multirow{3}{*}{0,765} \\
\hline & De uma forma geral, os anúncios não apresentam uma imagem fiel do produto anunciado. & \\
\hline & A maior parte da publicidade insulta a inteligência do consumidor. & \\
\hline \multirow{4}{*}{$\begin{array}{l}\text { Corrupção } \\
\text { de valores }\end{array}$} & A publicidade promove valores indesejáveis na nossa sociedade. & \multirow{4}{*}{0,837} \\
\hline & A maior parte da publicidade distorce os valores da juventude. & \\
\hline & A publicidade faz as pessoas viverem num mundo de fantasia. & \\
\hline & A publicidade persuade as pessoas a comprarem coisas que não deveriam. & \\
\hline
\end{tabular}




\begin{tabular}{|c|c|c|}
\hline Dimensões & Itens & $\begin{array}{l}\text { Alpha de } \\
\text { Cronbach }\end{array}$ \\
\hline \multicolumn{3}{|c|}{ Atitude geral face à publicidade } \\
\hline \multirow{3}{*}{$\begin{array}{c}\text { Atitude } \\
\text { geral face à } \\
\text { publicidade }\end{array}$} & Em geral, gosto de publicidade. & \multirow{3}{*}{0,817} \\
\hline & A minha opinião geral sobre a publicidade é favorável. & \\
\hline & De uma forma geral, considero a publicidade uma coisa boa. & \\
\hline \multicolumn{3}{|c|}{ Influência da publicidade na decisão de compra } \\
\hline \multirow{4}{*}{$\begin{array}{c}\text { Influência na } \\
\text { decisão de } \\
\text { compra }\end{array}$} & Uso informação dos anúncios publicitários para me ajudar a tomar decisões de compra. & \multirow{4}{*}{0,754} \\
\hline & $\begin{array}{l}\text { Os anúncios publicitários ajudam-me a recordar os produtos e as marcas quando os vou } \\
\text { comprar. }\end{array}$ & \\
\hline & $\begin{array}{l}\text { A informação que vejo na publicidade é útil quando estou a decidir que marca ou produto } \\
\text { comprar. }\end{array}$ & \\
\hline & $\begin{array}{l}\text { A publicidade influencia as minhas opiniões e sentimentos acerca das marcas e dos } \\
\text { produtos. }\end{array}$ & \\
\hline
\end{tabular}

Fonte: elaboração dos autores, com base no modelo de Pollay e Mittal.

\section{Análise das crenças e da atitude face à publicidade na perspetiva dos jovens consumidores}

Uma vez reduzidos os vários itens da escala às dimensões essenciais e, portanto, às variáveis latentes a analisar, procedemos à sua análise descritiva (Tabela 3). Recorda-se que a escala de classificação usada pelos entrevistados contemplava cinco níveis: 1 = discordo totalmente; 2 = discordo; $3=$ indiferente $4=$ concordo $; 5=$ concordo totalmente.

Começando pela utilidade da publicidade ao nível pessoal, sobressaem duas dimensões que alcançaram um valor positivo moderado - Informação na publicidade e Entretenimento na publicidade - mostrando que, por um lado, os entrevistados consideram que a publicidade transmite informação sobre os produtos e que, por outro lado, ela os diverte e entretém. É com indiferença que os indivíduos encaram o papel social da publicidade, ou seja, o de mostrar o que está na moda e o que comprar para impressionar os outros.

Relativamente aos efeitos sociais e culturais da publicidade, todas as dimensões apresentam alguma importância para os consumidores. Nesse contexto, se, por um lado, a publicidade é vista como benéfica para a economia, por outro lado, também lhe são atribuídos efeitos negativos, tais 
como os de incitadora do materialismo, enganosa, confusa e deturpadora dos valores.

Em geral, os sujeitos apresentam uma atitude positiva sobre a publicidade, mas são mais moderados, quase indiferentes, quando se trata de assumir que esta tem uma influência importante no processo de decisão de compra.

\section{Tabela 3. Análise descritiva das variáveis}

\begin{tabular}{|l|c|c|c|c|}
\hline \multicolumn{1}{|c|}{ Dimensões } & Min. & Máx. & Média & Desvio padrão \\
\hline Informação na publicidade & 1,33 & 5,00 & 3,67 & 0,68 \\
\hline Papel social da publicidade & 1,00 & 4,67 & 2,85 & 0,83 \\
\hline Entretenimento na publicidade & 1,00 & 5,00 & 3,51 & 0,78 \\
\hline Materialismo & 1,00 & 5,00 & 3,74 & 0,83 \\
\hline Benefício para a economia & 1,67 & 5,00 & 3,43 & 0,64 \\
\hline Falsidade / sem sentido & 1,33 & 5,00 & 3,22 & 0,77 \\
\hline Corrupção de valores & 1,00 & 5,00 & 3,29 & 0,79 \\
\hline Atitude geral face à publicidade & 1,00 & 5,00 & 3,74 & 0,68 \\
\hline Influência na decisão de compra & 1,00 & 5,00 & 3,08 & 0,80 \\
\hline
\end{tabular}

Fonte: elaboração dos autores.

\section{Análise correlacional das dimensões do modelo}

O modelo proposto por Pollay e Mittal (1993) apresenta um conjunto de relações entre variáveis. Procurando fazer uma primeira interpretação dessas relações, foi levada a cabo uma análise correlacional das variáveis utilizando o coeficiente de correlação de Pearson. Essa prova permite verificar a associação linear entre variáveis quantitativas e pode variar entre -1 e 1, sendo que, quanto mais próximo desses extremos estiver o valor da correlação, maior é a intensidade dessa associação (Pestana e Gageiro, 2005). Essa associação pode ser positiva, se os aumentos de uma variável estão associados aos aumentos de outra variável, e pode ser negativa, se a variação entre as variáveis for em sentido contrário. A prova é considerada válida se tiver significância estatística, isto é, se o valor de significância for igual ou inferior a 0,05 .

Analisando os resultados obtidos, é possível constatar que praticamente todas as correlações apresentam significância estatística (Tabela 4). 
À semelhança do modelo original, as variáveis relativas à utilidade da publicidade ao nível pessoal apresentam uma correlação positiva com a "Atitude geral face à publicidade". As variáveis relativas aos efeitos sociais e culturais da publicidade mostram correlações negativas com a "Atitude geral face à publicidade", à exceção da consequência para a economia. As variáveis que apresentam correlações positivas mais fortes com a atitude perante a publicidade são a "Informação na publicidade", o "Entretenimento na publicidade", o "Papel social da publicidade" e "Benefício para a economia".

\section{Tabela 4. Análise correlacional das dimensões do modelo}

\begin{tabular}{|l|c|c|c|c|c|c|c|c|}
\hline & 1. & 2. & 3. & 4. & 5. & 6. & 7. & 8. \\
\hline 1. Atitude geral face à publicidade & - & & & & & & & \\
\hline 2. Informação na publicidade & $0,564^{* *}$ & & & & & & & \\
\hline 3. Papel social da publicidade & $0,365^{* *}$ & $0,472^{* *}$ & & & & & & \\
\hline 4. Entretenimento na publicidade & $0,519^{* *}$ & $0,323^{* *}$ & $0,443^{* *}$ & & & & & \\
\hline 5. Materialismo & $-0,163^{*}$ & $-0,102$ & $-0,021$ & $-0,079$ & & & & \\
\hline 6. Benefício para a economia & $0,382^{* *}$ & $0,329^{* *}$ & $0,351^{* *}$ & $0,315^{* *}$ & $-0,029$ & & & \\
\hline 7. Falsidade / sem sentido & $-0,286^{* *}$ & $-0,210^{* *}$ & $-0,037$ & $-0,081$ & $0,383^{* *}$ & $-0,159^{*}$ & & \\
\hline 8. Corrupção de valores & $-0,252^{* *}$ & $-0,103$ & $-0,018$ & $-0,107$ & $0,546^{* *}$ & $-0,170^{*}$ & $0,713^{* *}$ & \\
\hline 9. Influência na decisão de compra & $0,337^{* *}$ & $0,416^{* *}$ & $0,362^{* *}$ & $0,304^{* *}$ & $-0,141^{*}$ & $0,407^{* *}$ & $-0,173^{*}$ & $-0,173^{*}$ \\
\hline
\end{tabular}

Fonte: elaboração dos autores.

As três variáveis relativas à utilidade da publicidade ao nível pessoal, assim como a dimensão "Benefício para a economia", correlacionam-se positivamente com a "Influência na decisão de compra". As restantes dimensões relativas aos efeitos sociais e culturais da publicidade correlacionam-se negativamente com a "Influência na decisão de compra". Finalmente, a "Atitude geral face à publicidade" relaciona-se positivamente com a "Influência na decisão de compra”.

\section{Dimensões que permitem predizer a atitude face à publicidade}

No sentido de aferir quais as dimensões que permitem predizer a atitude com relação à publicidade, e responder assim ao objetivo 6, realizou-se uma regressão linear múltipla, utilizando o método stepwise. 
A regressão consiste num modelo estatístico que permite prever o comportamento de uma variável dependente, a partir de uma ou várias variáveis independentes. Quando se utiliza apenas uma variável independente, trata-se de uma regressão linear simples; quando se utiliza mais do que uma variável independente, estamos perante uma regressão linear múltipla (Pestana e Gageiro, 2005).

Nesta análise, assumiram-se as três dimensões relativas à utilidade da publicidade ao nível pessoal e as quatro dimensões relativas aos efeitos sociais e culturais da publicidade como variáveis independentes e usou-se a atitude geral face à publicidade como variável dependente.

O coeficiente de determinação R tem tendência a ser influenciado pela dimensão da amostra e pela dispersão dos dados e é uma medida da qualidade do ajustamento (Pestana e Gageiro, 2005). O R2 ajustado é frequentemente utilizado quando os modelos possuem mais do que uma variável independente, como é o caso do presente modelo. Analisando os presentes resultados, pode constatar-se que o modelo encontrado explica $47 \%$ da atitude geral perante a publicidade (Tabela 5). Isso significa que $47 \%$ da variação média da atitude geral sobre a publicidade são determinados pelos valores das variáveis independentes já referidas.

Das sete dimensões usadas como variáveis independentes, apenas quatro foram retidas no modelo, apresentando significância estatística $(<0,05)$. As dimensões "Papel informativo" e "Papel hedónico", relativas à utilidade da publicidade ao nível pessoal, são aquelas que melhor permitem explicar, de uma forma positiva, a atitude geral face à publicidade. Essas duas são as variáveis independentes que mais importância apresentam no modelo. Os valores $\beta$ indicam os efeitos provocados por cada uma das variáveis independentes na variável dependente.

Relativamente aos efeitos sociais e culturais da publicidade, são as dimensões "Benefício para a economia", positivamente, e a "Corrupção de valores”, negativamente, que explicam a atitude geral face à publicidade. 
Esses resultados são consistentes com os resultados obtidos por Pollay e Mittal, à exceção da dimensão "Corrupção de valores". No estudo original, foi retida no modelo a dimensão "Falsidade e contrassenso", ao invés daquela. Não obstante, tanto no estudo original como no presente estudo, a contribuição dessas variáveis para o modelo é ténue.

\section{Tabela 5. Predição da atitude geral face à publicidade}

\begin{tabular}{|c|c|c|c|}
\hline \multirow{2}{*}{ Dimensões (variáveis independentes) } & \multicolumn{3}{|c|}{ Atitude geral face à publicidade (variável dependente) } \\
\cline { 2 - 4 } & $\boldsymbol{\beta}$ & t-value & Sig. \\
\hline Papel informativo & 0,401 & 7,308 & 0,000 \\
\hline Papel social & 0,026 & 0,420 & 0,675 \\
\hline Papel hedónico & 0,336 & 6,166 & 0,000 \\
\hline Materialismo & $-0,011$ & $-0,186$ & 0,853 \\
\hline Benefício para a economia & 0,118 & 2,137 & 0,034 \\
\hline Falsidade e contrassenso & $-0,097$ & $-1,324$ & 0,187 \\
\hline Corrupção de valores & $-0,154$ & $-3,023$ & 0,003 \\
\hline $\mathrm{R}^{2}$ & & 0,474 & \\
\hline
\end{tabular}

Fonte: elaboração dos autores.

Por meio do mesmo método, procurou-se aferir até que ponto a "Atitude geral face à publicidade" permite predizer a "Influência na decisão de compra” (Tabela 6). As dimensões em causa foram usadas como variável independente e dependente, respetivamente. A "Atitude geral face à publicidade" permite explicar 10\% da "Influência na decisão de compra", tendo a variável independente um impacto moderado na variável dependente.

\section{Tabela 6. Predição da influência na decisão de compra}

\begin{tabular}{|c|c|c|c|}
\hline \multirow{2}{*}{ Dimensão (variáveis independentes) } & \multicolumn{3}{|c|}{ Influência na decisão de compra (variável dependente) } \\
\cline { 2 - 4 } & $\boldsymbol{\beta}$ & $\mathbf{t}$-value & Sig. \\
\hline Atitude geral face à publicidade & 0,337 & 5,165 & 0,000 \\
\hline $\mathrm{R}^{2}$ & \multicolumn{3}{|c}{0,109} \\
\hline
\end{tabular}

Fonte: elaboração dos autores. 
Finalmente, os dois modelos aqui abordados são sintetizados na Figura 1.

\section{Figura 1. Modelo síntese da predição da atitude geral face à publicidade e da influência na decisão de compra}

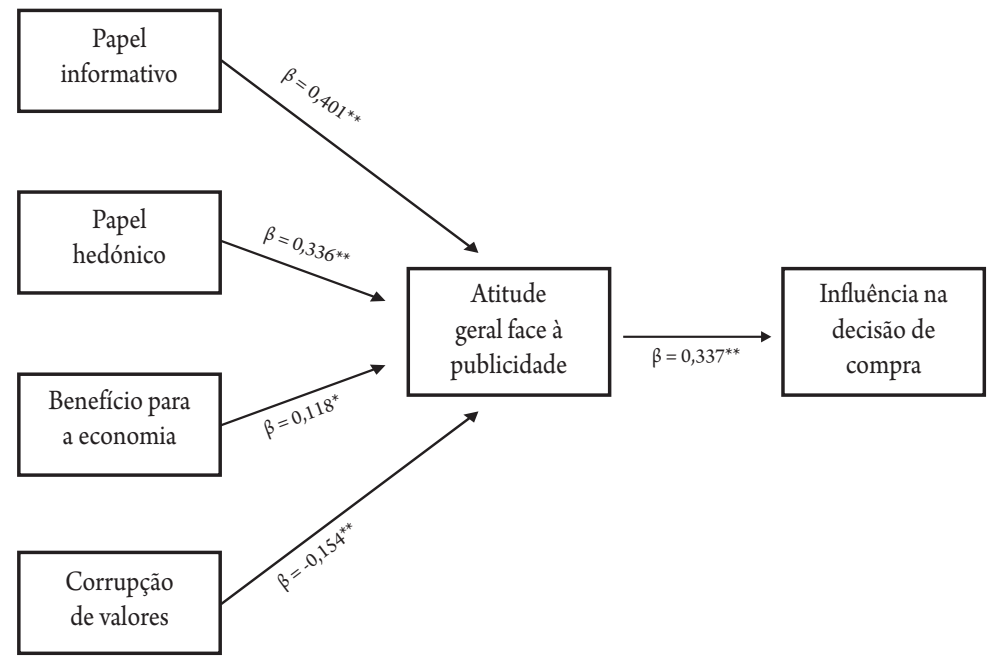

Legenda: * $<0,05 ;{ }^{* *}<0,01 ; \beta-$ coeficiente beta.

Fonte: elaboração dos autores.

\section{Conclusões e discussão}

A diversidade das reações ao fenómeno publicitário é empiricamente verificável. Ela pode explicar-se, pelo menos parcialmente, devido às caraterísticas particulares que definem esse discurso (ver, entre outros, Freitas, 2012). Neste estudo, procurou-se, em primeiro lugar, avaliar o modo como os adultos jovens portugueses se posicionam relativamente à publicidade e aos seus efeitos em diferentes aspetos da vida contemporânea. Para esse efeito, e numa perspetiva essencialmente exploratória, analisou-se a aplicabilidade do instrumento criado por Pollay e Mittal (1993) aos consumidores jovens adultos portugueses. Em concreto, pretendeu-se confirmar a consistência das dimensões propostas no modelo.

Após a análise do Alpha de Cronbach das dimensões que constituem o modelo, verificou-se que as dimensões apresentam uma consistência in- 
terna aceitável, com valores, na sua maioria, iguais ou superiores a $\alpha=0.70$. Esses resultados demonstram a transversalidade geográfica da escala criada por Pollay e Mittal (1993) e constituem um contributo útil ao nível académico, nomeadamente para futuras utilizações do instrumento em Portugal.

Nesta investigação, os autores propuseram-se levar a cabo uma análise de dados introdutória por meio da observação dos valores médios de todas as dimensões do modelo e a influência no processo de decisão de compra.

Tomando como ponto de partida a utilidade da publicidade ao nível pessoal, sobressaem duas dimensões que alcançaram um valor positivo moderado: "Papel informativo" e "Papel hedónico". Os resultados mostram que os consumidores estão atentos a esse tipo de comunicação e que retiram dela dois tipos de valias: a publicidade é útil para os consumidores porque lhes dá, acima de tudo, informação sobre o produto e sobre as novidades do mercado. Por outro lado, pode proporcionar-lhes momentos de entretenimento e emoção, desde que, naturalmente, as campanhas possuam, na sua estrutura, elementos com essas caraterísticas. Esses resultados devem ser levados em conta pelos profissionais de marketing e de publicidade. Assim, as campanhas publicitárias devem, em primeiro lugar, transmitir um conjunto de informações sucintas e claras sobre o produto, mas também, sempre que possível, incorporarem uma componente criativa, que contemple a atratividade da mensagem e a sua capacidade para interpelar o sentido lúdico do recetor.

Os efeitos sociais e culturais da publicidade também são percecionados pelos indivíduos. Nesse caso, salienta-se um aspeto positivo: a publicidade é benéfica para a economia, não sendo vista como um desperdício de recursos económicos, na medida em que promove a concorrência, o que, indiretamente, beneficia o consumidor (Freitas e Tuna, 2010).

No entanto, há igualmente aspetos negativos percecionados pelos consumidores. A publicidade pode incitar ao consumismo, deturpando os valores, enganando e, por vezes, suscitando confusão. Esses aspetos são alvo de críticas, tendo em vista que o fenómeno publicitário parece, por vezes, 
ser lido como estando desfasado relativamente às questões mais prementes na sociedade contemporânea, que parece exigir posicionamentos de honestidade e consonância para com as reais necessidades dos consumidores (Freitas e Tuna, 2015). Consequentemente, os resultados nesses parâmetros devem constituir sinais de alerta para os profissionais, concretamente no sentido de serem evitados conteúdos e abordagens criativas que possam suscitar esse tipo de leituras.

Partindo do modelo já mencionado, pretendia-se verificar a relação entre as crenças relativas à publicidade, a atitude face à publicidade e a influência desta na decisão de compra. Realizou-se uma correlação de Pearson que permitiu verificar que, à semelhança do modelo original, as variáveis relativas à utilidade da publicidade ao nível pessoal se relacionam positivamente com a "Atitude geral face à publicidade". As variáveis relativas aos efeitos sociais e culturais da publicidade mostram correlações negativas com a "Atitude geral face à publicidade”, à exceção da consequência para a economia. Finalmente, a "Atitude geral face à publicidade" relaciona-se positivamente com a "Influência na decisão de compra".

Os resultados obtidos permitem confirmar, até certo ponto, o modelo proposto por Pollay e Mittal (1993) e avançar para o passo seguinte, ou seja, a verificação das dimensões que permitem predizer a atitude face à publicidade. Uma regressão linear múltipla permitiu chegar a um modelo que explica quase $50 \%$ da atitude geral face à publicidade. As dimensões "Papel informativo" e "Papel hedónico", relativas à utilidade da publicidade ao nível pessoal, são aquelas que melhor permitem explicar, de uma forma positiva, a atitude geral face à publicidade. Essas duas são as variáveis independentes que mais importância apresentam no modelo. Assim, vemos que o papel informativo e o papel hedónico são fundamentais para a atitude que o consumidor constrói com relação à publicidade. Isso significa que as campanhas publicitárias devem apostar fortemente na objetividade dos argumentos e na apresentação de factos. No entanto, por outro lado, é igualmente importante o desenvolvimento de estratégias criativas que ofereçam ao consumidor um envolvimento emocional com a marca ou, pelo menos, um momento de prazer ou de entretenimento no momento do visiona- 
mento da mensagem publicitária (Geuens, De Pelsmaker e Faseur, 2011). Essas duas abordagens, racional e emocional, podem ser usadas estrategicamente de uma forma alternada ou de uma forma conjugada, reforçando ambas as dimensões. Estudos anteriores (Canedo, 2010; Bülbül e Menon, 2010) analisam diferentes tipos de emoção e a sua correlação com decisões de compra a curto ou a longo prazo.

Finalmente, foi possível verificar que a atitude geral face à publicidade explica $10 \%$ da influência na decisão de compra. Esse resultado conduz à conclusão de que, para o consumidor, é mais fácil admitir uma atitude positiva face à publicidade do que aceitar que esta possa resultar numa influência efetiva no processo de compra. Porém, embora a publicidade tenha como fim último levar à ação, existem outros objetivos preliminares que são igualmente importantes. Entre estes, podemos apontar a criação de notoriedade quanto à marca ou produto. Nesse sentido, as componentes informativa e racional desempenham um papel essencial (McKay-Nesbitt, Manchanda, Smith e Huhmann, 2011).

Este trabalho apresenta um conjunto de resultados que podem ser relevantes, quer ao nível académico, quer ao profissional. No entanto, existem limitações a este estudo que devemos assinalar. Nesse sentido, destacamos a dimensão reduzida da amostra. Esta incide essencialmente num determinado segmento etário, não contemplando outras faixas que poderiam contribuir para delinear o consumidor português de forma mais completa. Igualmente de assinalar é o facto de o modelo em causa ser essencialmente teórico, apesar das implicações positivas para o mercado anteriormente mencionadas. Essa caraterística cria a necessidade de se propor uma abordagem complementar que envolva componentes práticas mais específicas e, consequentemente, mais próximas da atividade dos profissionais de marketing e publicidade.

Desse modo, a utilização conjunta dessas escalas com outras dimensões relativas à abordagem criativa das campanhas publicitárias poderá ser um caminho a seguir em investigações futuras e poderá resultar em anúncios que evitem posicionar-se no espetro mais negativo das apreciações 
sobre o fenómeno publicitário. Isso permitiria evitar a ativação das atitudes negativas dos consumidores, que poderiam refletir-se de forma desvantajosa sobre o produto ou o serviço divulgado. Por outro lado, enquanto fenómeno que representa uma das manifestações mais visíveis das várias evoluções sociais, seria igualmente vantajoso, de uma forma global, que estudos deste cariz pudessem contribuir para a existência de uma publicidade mais responsável. Assim, seria possível incentivar formas de consumo mais regradas e equilibradas.

\section{Referências}

Bülbül, C. e Menon, G. (2010). The power of emotional appeals in advertising: the influence of concrete versus abstract affect on time-dependent decisions. Journal of Advertising Research, 50(2), 169-180.

Bush, A., Smith, R. e Martin, C. (1999). The Influence of Consumer Socialization Variables on Attitude Toward Advertising: A Comparison of African-Americans and Caucasians. Journal of Advertising, 27(3), 13-24.

Canedo, E. (2010). Atitude dos consumidores face aos apelos emocionais e racionais da publicidade: estudo do sector alimentar (Dissertação de Mestrado). Faculdade de Economia da Universidade do Porto, Portugal.

Cardal, N. e Almeida, R. F. (1994). Grupo McCann Portugal — 65 anos de publicidade. Lisboa: Texto Editora.

Cornelis, E., Adams, L. e Cauberghe, V. (2012). The effectiveness of regulatory (in)congruent ads: The moderating role of an ad's rational versus emotional tone. International Journal of Advertising, 31(2), 397-420.

Cunha, C. e Freitas, E. S. (2010). Uma análise dos novos média e a criação de conteúdos como estratégia publicitária para o sucesso das marcas. Cadernos de Estudos Mediáticos, 7, 29-42. 
Dávila, V. R. e Rojas-Méndez, J. I. (2001). Attitudes Toward Advertising: How Does the 7-Factor Model Work in Chile? International Journal of Organization Theory and Behavior, 4(1-2), 3-19.

Dutta-Bergman, M. (2006). The demographic and psychographic antecedents of attitude toward advertising, Journal of Advertising Research, 46(1), 102-112.

Freitas, E. S. (2008). Taboo in Advertising. Amsterdam e Philadelphia: John Benjamins.

Freitas, E. S. (2012). Advertising and Discourse Analysis. Em J. P. Gee e M. Handford (eds.), The Routledge Handbook of Discourse Analysis (pp. 427-440). Londres; Nova York: Routledge; Taylor e Francis.

Freitas, E. S. (2014). Language of Advertising. Em C. Leung e B. V. Street (eds.), The Routledge Companion to English Studies (pp. 505-515). Londres; Nova York: Routledge; Taylor e Francis.

Freitas, E. S. e Tuna, S. G. (2010). Comunicação publicitária em tempos de crise: análise discursiva de estratégias de honestidade em duas campanhas "estilo de vida". Cadernos de Estudos Mediáticos, 7, 15 - 27.

Freitas, E. S. e Tuna, S. G. (2015). Novas metodologias e abordagens em apelos publicitários: formas responsáveis de consumo na publicidade contemporânea. LABCOM Estudos em Comunicação/Communication Studies: Advanced Methodologies in Communication Studies (Special Issue), 19, 159-176.

Gazeta do Rossio (5 de fevereiro de 2015). Jovens portugueses usam mais a internet para ver notícias. Gazeta do Rossio. Recuperado em 31 mar. 2016 de http://www.orossio.pt/jovens-portugueses-usam-mais-a-internet-para-ler-noticias.html

Geuens, M., De Pelsmaker, P. e Faseur, T. (2011). Emotional advertising: Revisiting the role of product category. Journal of Business Research, 64, 418-426. 
Greyser, S. e Bauer, R. (1966). Americans and advertising: thirty years of public opinion. The Public Opinion Quarterly, 30(1), 69-78.

Larkin, E. F. (1977). A Factor Analysis of College Student Attitudes Toward Advertising. Journal of Advertising, 6(2), 42-46.

Lindon, D., Lendrevie, J., Lévy, J., Dionísio, P. e Rodrigues J. (2008). Mercator XXI: Teoria e Prática do Marketing. 11. ed. Lisboa: Publicações Dom Quixote.

Hilliard, H., Matulich, E., Haytko, D. e Rustogi, H. (2012). An International Look at Attitude Toward Advertising, Brand Considerations, and Market Expertise: United States, China and India. Journal of International Business Research, 1, 29-41.

Mady, T., Cherrier, H., Lee, D. e Rahman, K. (2011). Can Sentiment Toward Advertising Explain Materialism and Vanity in the Globalization Era? Evidence From Dubai. Journal of Global Marketing, 24, 453-472.

Marin, E. R., Pizzinato, N. K. e Giuliani, A. C. (2014). Rational and Emotional Communication in Advertising in Women's Magazines in Brazil. Brazilian Business Review, nov.-dez., 22-49.

Marinov, M., Petrovici, D. e Marinova, S. (2008). Consumer Attitudes Toward Advertising in Bulgaria and Romania. Joumal of Euromarketing, 17(2), 81-93.

Marktest (29 de setembro de 2015). Metade do investimento publicitário em 20 anunciantes. Grupo Marktest. Recuperado em 31 mar. 2016 de http://www.marktest.com/wap/a/n/id 1f89.aspx

Maroco, J. e Garcia-Marques, T. (2006). Qual a fiabilidade do alfa de Cronbach? Questões antigas e soluções modernas? Laboratório de Psicologia, 4(1), 65-90. 
Martin-Santana, J. D. e Beerli-Palacio, A. (2008). Why Attitudes Toward Advertising Are Not Universal: Cultural Explanations. Journal of Euromarketing, 17(3-4), 159-181.

McKay-Nesbitt, J., Manchanda, R. V., Smith, M. C. e Huhmann, B. A. (2011). Effects of age, need for cognition, and affective intensity on advertising effectiveness. Journal of Business Research, 64, 12-17.

Muehling, D. (1987). An investigation of factors underlying Attitudes-TowardsAdvertising-In-General. Journal of Advertising, 16(1), 32-40.

Nan, X. (2006). Perceptual Predictors of Global Attitude toward Advertising: An Investigation of Both Generalized and Personalized Beliefs. Journal of Current Issues and Research in Advertising, 28(1), 31-44.

Nunnally, J. (1978). Psychometric theory. Nova York: McGraw-Hill Inc.

Pestana, M. H. e Gageiro, J. N. (2005). Análise de dados para ciências sociais. A complementaridade do SPSS. 4. ed. rev. e aument. Lisboa: Edições Sílabo.

Petrovici, D. e Paliwoda, S. (2007). An empirical examination of public attitudes towards advertising in a transitional economy. International Journal of Advertising, 26(2), 247-276.

Pollay, R. W. e Mittal, B. (1993). Here's the Beef: Factors, Determinants, and Segments in Consumer Criticism of Advertising. Journal of Marketing, 57, 98-114.

Prendergast, G., Wah-leung, C. e West, D. (2010). Antecedents to Advertising Avoidance in China. Journal of Current Issues e Research in Advertising, 32(2), 87-100.

Ramaprasad, J. (2001). South Asian Students' Beliefs About and Attitude Toward Advertising. Journal of Current Issues and Research in Advertising, 23(1), 55-70. 
Ribeiro, S. (14 de dezembro de 2015). Investimento publicitário em Portugal terá crescido 4\% em 2015 para 500 milhões. Jornal de Negócios. Recuperado em 31 mar. 2016 de http://www.jornaldenegocios. pt/empresas/detalhe/investimento_publicitario_em_portugal_ tera_crescido_4_em_2015_para_500_milhoes.html

Shavitt, S., Lowrey, P. e Haefner, J. (1998). Public attitudes toward advertising: more favorable than you might think. Journal of Advertising Research, 38(4), 7-22.

Silva, S. P., Torres, R. e Freitas, E. S. (2014). A Comunicação lúdica no anúncio publicitário: o jogo discursivo com o leitor. Em I. Patim, D. Seabra, R. Estrada e F. Hilário (eds.), Literatura e Jogo: Narrativas, Discursos, Representações e Mitos (pp. 305-317). Lisboa: Esfera do Caos.

Williams, P. e Drolet, A. (2005). Age-Related Differences in Responses to Emotional Advertisements. Journal of Consumer Research, 32, 343-354.

Yang, C. (2000). Taiwanese students' attitudes towards and beliefs about advertising. Journal of Marketing Communications, 6, 171-183. 